\title{
Speech sound production accuracy produced by North Korean defectors' adolescent children born in China
}

\author{
Eun Kyoung Lee', Hyun Jung Lee ${ }^{2}$ \\ 'Department of Speech-Language Therapy, Dongshin University, Naju; ${ }^{2}$ Department of Speech-Language Pathology, Honam University, Gwangju, \\ Korea
}

Purpose: Children from North Korean defector families possess different characteristics from children with other multicultural and multilingual backgrounds in Korea, partially due to the fact that the number of children born in third countries is higher than those of children born in North Korea. The purpose of the study is to analyze the word-level speech sound productions of adolescent children of North Korean refugee mothers, primarily through a calculation of speech sound accuracy.

Methods: The participants consisted of 11 adolescent children whose mothers were North Korean defectors, and whose fathers were Chinese. Participants' speech sound production skills were assessed using 103 words from the KS-PAPT and U-TAP.

Results: Korean defectors' adolescent children have lower consonant accuracy (PCC = $79.14 \%$ ) compared to vowel accuracy (PVC=94.71\%). The consonant accuracy of liquid / ᄅ / was significantly lower than those of other manners of articulation. The consonant accuracy of word-final codas was significantly lower than those of other positions in word.

Conclusions: This current research has clinical implications for the assessment and analysis of the speech production abilities of the adolescent children of North Korean refugees.

Keywords: speech sound production, migrant youth, North Korean defectors, PCC

\section{INTRODUCTION}

The growing number of immigrants and foreign workers has led to an increase in the number of linguistic minorities currently residing in Korea [1]. Among them, children from North Korean defector families possess different characteristics from children with other multicultural and multilingual backgrounds in Korea, partially due to the fact that the number of children born in third countries is higher than those of children born in North Korea [2].

Many of the children of North Korean defector families were born and raised in China. They learn Korean as a second language after Chinese, which is established as their first language [3]. When examining second language acquisition, the interference of the first language should be considered, since the errors in the early stage of second language learning reflects the characteristics of the first language [4]. They perceive and articulate Korean phonemes based on the already established Chinese phoneme sys-

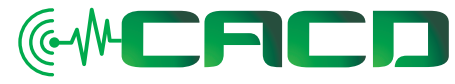

Received: July 29, 2021

Revision: August 20, 2021

Accepted: August 20, 2021

Correspondence:

Hyun Jung Lee

Department of Speech-Language Pathology, Honam University, 120 Honamdae-gil, Gwangsan-gu, Gwangju 62399, Korea

Tel: +82-62-940-5520

Fax: +82-62-940-5925

E-mail: slplee@honam.ac.kr

(C) 2021 The Korean Association of SpeechLanguage Pathologists

This is an Open Access article distributed under the terms of the Creative Commons Attribution NonCommercial License (https://creativecommons.org/ licenses/by-nc/4.0/) which permits unrestricted noncommercial use, distribution, and reproduction in any medium, provided the original work is properly cited. 
tem, which makes it difficult for them to accurately perceive and articulate Korean, which can lead to communication disorders $[5,6]$.

\section{Phonological systems of Korean and Chinese}

According to Kim and Shin [7], the syllable structure of Korean is [C0-1]-V-[C0-1] (Table 1). The 18 initial consonants are

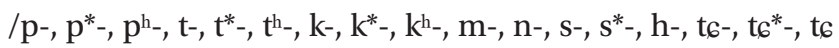
$\mathrm{h}-, \mathrm{l}-/$; the 7 vowels are / i, $\varepsilon, \mathrm{a}, \Lambda, \mathrm{o}, \mathrm{u}, \mathrm{w} /$; the 10 diphthongs are

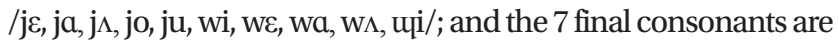
/-p, -t, -k, -l, -m, -n, - -n/.

Meanwhile, Chinese has 21 initial consonants, /p-, $\mathrm{p}^{\mathrm{h}}-$, t-,

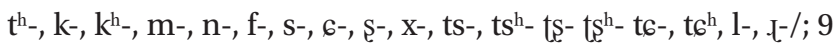
vowels, /i, u, y, o, A, ə, ə, u, r/; 10 diphthongs, /ae, ei, ao, ow, ia, ie, iu, uo, uA, ye/; 4 triphthongs, /iao, iow, uae, uei/; and 2 final consonants, /-n, $-\mathrm{n} /[8]$.

However, simply analyzing the differences in the phonological systems of the two languages cannot fully explain the nature of the learners' errors. This is because the errors occur not only in different sounds, but also in similar sounds between the phonological systems. For the intervention of speech sound disorders of bilingual speakers, it is necessary to categorize errors that appear in each language population, and to specifically suggest effective intervention programs in order to reduce them.

The purpose of the study is to analyze the word-level speech sound productions of adolescent children of North Korean refugee mothers, primarily through a calculation of speech sound accuracy. It will contribute towards finding an effective way to teach the Korean language to children and adults

Table 1. Phonological Systems of Korean and Chinese

\begin{tabular}{|c|c|c|}
\hline & Korean & Chinese (Putonghua) \\
\hline \multirow[t]{5}{*}{ Initial consonants } & $\mathrm{p} \mathrm{p}^{*} \mathrm{p}^{\mathrm{h}} \mathrm{t} \mathrm{t}^{*} \mathrm{t}^{\mathrm{h}} \mathrm{k} \mathrm{k}^{*} \mathrm{k}^{\mathrm{h}}$ & $\mathrm{p} \mathrm{p}^{\mathrm{h}} \mathrm{t} \mathrm{t}^{\mathrm{h}} \mathrm{k} \mathrm{k}^{\mathrm{h}}$ \\
\hline & $\mathrm{s}, \mathrm{s}^{*}, \mathrm{~h}$ & fs $6 \mathrm{~s} x$ \\
\hline & $\mathrm{t} 6 \mathrm{t} 6^{*} \mathrm{t}^{\mathrm{h}}$ & ts ts ${ }^{h} t s t s^{h} t \in t c^{h}$ \\
\hline & $\mathrm{mn}$ & $\mathrm{m} \mathrm{n}$ \\
\hline & 1 & $1_{t}$ \\
\hline Final consonants & $\mathrm{ptk} 1 \mathrm{mnn}$ & $\mathrm{n \eta}$ \\
\hline \multirow[t]{2}{*}{ Vowels } & i $\varepsilon a \Lambda$ o u u & iuyo A $ə \partial$ ur \\
\hline & 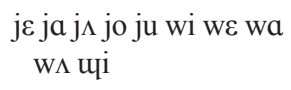 & $\begin{array}{l}\text { ae ei ao ow ia ic iu uo } \\
\text { uA ye iao iow uae uei }\end{array}$ \\
\hline Syllable structures & {$[\mathrm{C} 0-1]-\mathrm{V}-[\mathrm{C} 0-1]$} & {$[\mathrm{C} 0-1]-\mathrm{V}-[\mathrm{C} 0-1]$} \\
\hline Tones & N/A & $\begin{array}{l}\text { high level, high rise, } \\
\text { falling-rising, high } \\
\text { falling, neutral }\end{array}$ \\
\hline
\end{tabular}

whose first language is Chinese.

\section{METHODS}

\section{Participants}

The participants consisted of 11 adolescent children whose mothers were North Korean defectors, and whose fathers were Chinese. There were six males and five females. Their primary language was Chinese. They were born in China, lived in China, and then moved to South Korea with their mother. Their chronological ages ranged from 9 to 19 years old. Their period of residence in South Korea ranged from 1 month to 3 years and 6 months, and their period of school education in South Korea ranged from 0 month to 2 years and 9 months. It was reported that they had no problems with hearing, oral structure and function, or cognitive ability from their parents or school teachers (Table 2).

\section{Tools and Procedures}

Participants' speech sound production skills were assessed using 103 words from the Korean Standard Picture of Articulation and Phonological Test (KS-PAPT) [9] and the Urimal Test of Articulation and Phonation (U-TAP) [10]. The KS-PAPT contains a total of 75 words. The U-TAP contains a total of 30 words (The words / $\mathrm{k}^{*}$ ori/ ('tale' in Korean) and /tcektcek/ ('tweet' in Korean) were included in both tests and tested once). The KS-PAPT allows for the phonological assessment of children aged 3 to 6 years old, and the U-TAP allows for the phonological assessment of children aged 2 to 6 years old. Both tests are used to assess children's speech sound produc-

Table 2. Participants information

\begin{tabular}{ccccccc}
\hline Participant & Age & $\begin{array}{c}\text { Residence } \\
\text { period }\end{array}$ & $\begin{array}{c}\text { Education } \\
\text { period }\end{array}$ & Gender & \multicolumn{2}{c}{ Parent nationality } \\
\hline 1 & $18 ; 5$ & $3 ; 6$ & $2 ; 4$ & M & China North Korea \\
\hline 2 & $17 ; 10$ & $2 ; 11$ & $1 ; 2$ & M & China North Korea \\
3 & $16 ; 6$ & $2 ; 9$ & $2 ; 9$ & M & China & North Korea \\
\hline 4 & $10 ; 8$ & $2 ; 8$ & $2 ; 8$ & M & China North Korea \\
\hline 5 & $17 ; 1$ & $2 ; 8$ & $2 ; 1$ & F & China North Korea \\
6 & $17 ; 2$ & $2 ; 2$ & $2 ; 1$ & M & China North Korea \\
7 & $19 ; 0$ & $2 ; 2$ & $2 ; 2$ & F & China North Korea \\
8 & $15 ; 7$ & $1 ; 11$ & $1 ; 6$ & M & China North Korea \\
9 & $17 ; 9$ & $1 ; 1$ & $0 ; 8$ & F & China North Korea \\
10 & $12 ; 8$ & $0 ; 9$ & $0 ; 8$ & F & China North Korea \\
11 & $9 ; 0$ & $0 ; 1$ & 0 & F & China North Korea \\
\hline
\end{tabular}


tion and provide normative data for the percentage of correct consonants (PCC).

\section{Data analysis}

The participants' speech sound accuracy was analyzed. The PCCs and the Percentage of Vowels Correct (PVCs) of 11 adolescent children of North Korean refugee mother were analyzed in total, and thereafter, the speech sound accuracy was further investigated according to the position in word and the place and manner of articulation.

The paired sample t-test was performed to compare the speech sound production accuracy according to the position in word and the place and manner of articulation.

\section{RESULTS}

\section{Percentage of consonants and vowels correct}

First, the PCCs and the PVCs of 11 adolescent children of North Korean refugee mothers were analyzed in total. The mean of PCCs of 11 adolescent children of North Korean refugee mothers was $79.14(\mathrm{SD}=9.69)$ (Table 3). Their PCCs ranged from 64.46 to 95.18. The mean of PVCs of 11 adolescent children North Korean refugee mothers was 94.71 (SD = 10.15). Their PVCs ranged from 65.38 to 100 . The results of the paired sample t-test show that the mean of PVCs was significantly higher than those of PCCs $(\mathrm{t}=5.386, p=0.000)$. However, the range of PVCs among participants was as large as that of PCCs.

\section{Speech production accuracy according to place of articulation}

Next, the speech production accuracy was analyzed according to place of articulation: The average accuracy of bilabial production was 78.44 ( $\mathrm{SD}=11.33$ ); the average accuracy of alveolar production was $79.62(\mathrm{SD}=9.93)$; the average accuracy of alveolo-palatal production was $73.03(\mathrm{SD}=16.52)$; the average accuracy of velars production was $78.45(\mathrm{SD}=11.85)$; and the average accuracy of glottal production was $97.40(\mathrm{SD}=5.78)$ (Table 4). The results of the paired sample t-test show that the mean of the accuracy of glottal production was significantly higher than those of bilabials $(t=5.796, p=0.000)$, those of al-

Table 3. Percentage of consonants and vowels correct

\begin{tabular}{llrl}
\hline Measures & Mean & \multicolumn{1}{c}{ SD } & \multicolumn{1}{c}{ Range } \\
\hline PCC & 79.14 & 9.69 & $64.46-95.18$ \\
PVC & 94.71 & 10.15 & $65.38-100$ \\
\hline
\end{tabular}

veolars $(\mathrm{t}=6.413, p=0.000)$, those of alveolo-palatals $(\mathrm{t}=4.598$, $p=0.001)$ and those of velars $(\mathrm{t}=7.006, p=0.000)$.

\section{Speech production accuracy according to manner of articulation}

Afterwards, the speech production accuracy was analyzed according to the manner of articulation: The average accuracy of plosive production was 80.68 ( $\mathrm{SD}=9.24$ ); the average accuracy of fricative production was $78.79(\mathrm{SD}=10.29)$; the average accuracy of affricates production was $75.40(\mathrm{SD}=13.62)$; the average accuracy of nasal production was $83.85(\mathrm{SD}=13.50)$; and the average accuracy of liquid production was 66.12 (SD = 20.10) (Table 5). The results of the paired sample t-test shows that the mean of the accuracy of liquid production was significantly lower than those of plosives $(\mathrm{t}=3.548, p=0.005)$ and those of nasals $(\mathrm{t}=2.783, p=0.019)$.

\section{Speech production accuracy according to position in word}

Lastly, the speech production accuracy was analyzed according to the position in the word: The average accuracy of wordinitial onsets production was $87.52(\mathrm{SD}=7.35)$; the average accuracy of word-medial onsets production was 84.05 (SD = 5.99); the average accuracy of word-medial codas production was 78.65 ( $\mathrm{SD}=19.08$ ); and the average accuracy of word-final codas production was $58.21(\mathrm{SD}=21.87)$ (Table 6$)$. The results of the paired sample t-test shows that the mean of the accuracy of word-final codas production was significantly lower than those of word-initial onsets ( $\mathrm{t}=5.327, p=0.000)$, those of word-medial onsets $(\mathrm{t}=4.491, p=0.001)$ and those of word-

Table 4. Speech production accuracy (\%) according to place of articulation

\begin{tabular}{lrrc}
\hline Measures & Mean & SD & Range \\
\hline Bilabial accuracy & 78.44 & 11.33 & $65.85-97.56$ \\
Alveolar accuracy & 79.62 & 9.93 & $64.71-97.06$ \\
Alveolo-palatal accuracy & 73.03 & 16.52 & $44.44-94.12$ \\
Velars accuracy & 78.45 & 11.85 & $60.61-93.94$ \\
Glottal accuracy & 97.40 & 5.78 & $85.71-100.00$ \\
\hline
\end{tabular}

Table 5. Speech production accuracy (\%) according to manner of articulation

\begin{tabular}{lcrl}
\hline Measures & Mean & SD & \multicolumn{1}{c}{ Range } \\
\hline Plosive accuracy & 80.68 & 9.24 & $66.25-97.50$ \\
Fricative accuracy & 78.79 & 10.29 & $61.90-95.24$ \\
Affricates accuracy & 75.40 & 13.62 & $47.06-94.12$ \\
Nasal accuracy & 83.85 & 13.50 & $54.29-100.00$ \\
Liquid accuracy & 66.12 & 20.10 & $30.77-100.00$ \\
\hline
\end{tabular}


Table 6. Speech production accuracy (\%) according to position in word

\begin{tabular}{lccc}
\hline Measures & Mean & \multicolumn{1}{c}{ SD } & Range \\
\hline Word-initial onset accuracy & 87.52 & 7.35 & $79.10-98.51$ \\
Word-medial onset accuracy & 84.05 & 5.99 & $73.58-92.45$ \\
Word-medial coda accuracy & 78.65 & 19.08 & $47.37-100.00$ \\
Word-final coda accuracy & 58.21 & 21.87 & $33.33-96.30$ \\
\hline
\end{tabular}

medial codas $(\mathrm{t}=3.903, p=0.003)$.

\section{DISCUSSION}

When working with multicultural children with speech sound disorders, it is necessary to classify the speech sound errors in which the L1 interference phenomenon is prominent and to develop systematic and effective intervention programs for them. This study aimed to explore the word-level speech production accuracy of the adolescent children of North Korean defectors born in China. We analyzed participants' speech sound accuracy from their productions of 103 words from KSPAPT and U-TAP.

First, the PCCs and the PVCs of 11 adolescent children of North Korean refugee mothers were analyzed in total. The analysis presented in this study highlights that North Korean defectors' adolescent children have lower consonant accuracy ( $\mathrm{PCC}=79.14 \%$ ) compared to vowel accuracy $(\mathrm{PVC}=94.71 \%$ ). Considering that they learned Korean as a foreign language before entering Korea, the PCC of $79 \%$ was lower than we expected. According to [11], a PCC of $79 \%$ indicates a mildmoderate disorder. These research results are consistent with previous studies that Chinese speakers learning Korean experience greater difficulties in consonants as opposed to vowels.

Although the overall mean of PVCs was higher than that of PCCs, the range of PVCs among 11 participants was as wide as that of PCCs. This findings suggests that vowel production should not be overlooked when exploring the speech sound accuracy in children from multilingual backgrounds.

Then, the speech production accuracy was further investigated according to place and manner of articulation and position in word. As a result of examining the speech production accuracy according to the place of articulation, the accuracy of the glottal / $\bar{c}$ / was significantly higher than those of other places of articulation. Except for the glottal sound, there was no significant difference in speech production accuracy according to place of articulation.

As a result of examining the speech production accuracy according to manner of articulation, the consonant accuracy of liquids / ᄅ / was significantly lower than those of other manners of articulation. For Chinese speakers learning Korean, Korean liquid is difficult to pronounce because the two languages have different phonological systems. Korean liquid has two allophones: flap [r] and lateral [l] whereas Chinese liquid is separated to two phonemes: retroflex [r] and dental [l] [12].

The influence of first language was also shown in the speech production accuracy according to the position in word. The consonant accuracy of word final codas was significantly lower than those of other positions in word. Korean final consonants are not easily recognizable compared to initial consonants because they are unreleased. It is more difficult for Chinese learners to perceive them because Chinese does not have a closing consonant ending. As in Chinese only /n/ and $/ \mathrm{y} /$ can come at the end of a syllable, Chinese learners tend to omit or substitute the Korean final consonants $[13,14]$.

This study provides an initial reference for the word-level speech production accuracy produced by North Korean defectors' adolescent children born in China. The study had a small sample size and did not include direct control groups. In follow-up studies, it is necessary to analyze the speech sound error patterns.

The basic purpose of speech rehabilitation is communication, and accurate pronunciation is important for good communication. This current research has clinical implications for the assessment and analysis of the speech production abilities of the adolescent children of North Korean refugees. To clinicians, it is important to identify significant speech sound production patterns in second language learners. Understanding the phonology of their native language would be helpful to differentiate patterns associated with speech differences with speech disorders.

\section{REFERENCES}

1. Choi LJ. Educating language minority students in South Korea: Multilingual sustainability and linguistic human rights. Sustainability. 2021;13:3122.

2. Choi IS. A study on the reality of immigrant youth from multicultural families and improvement methods to support multicultural education. Unpublished Master's thesis, Graduate School of Educational Policy and Administration of Korea National University of Education; 2018.

3. Baek GM. A Comparative study on the L1 and L2 acquisition of Korean language; Focus on phonology and morphology. Unpub- 
lished Doctor's thesis, Hanyang University. 2012.

4. Selinker L. Interlanguage; 1972.

5. Kim JY, Lee EK. Articulatory and phonological characteristics of North Korean immigrant children in the whole word analysis. Journal of Fisheries and Marine Sciences Education. 2019;31: 1387-1396.

6. Park DB, Kim JY, Lee EK. A study on percentage of correct consonant and phonological process characteristics for immigrated children of multicultural families. Proceedings from the 5th Joint Conference of the Korean Speech- Language and Hearing Association and Korean Academy of Speech-Language Pathology and Audiology. 2016;103-106.

7. Kim SJ, Shin JY. Speech Sound Disorders. Seoul: Sigmapress. 2015.

8. Dodd ZHB. Putonghua (modern standard Chinese)-speaking children with speech disorder. Clinical Linguistics \& Phonetics. 2000;14:165-191.
9. Seok D, Park S, Shin H, Park H. Korean Standard Picture of Articulation and Phonological Test (KS-PAPT). Seoul: Hakjisa; 2008.

10. Kim YT, Shin MJ, Kim SJ, Ha JW. Urimal test of articulation and phonology (U-TAP). Seoul: Hakjisa; 2004.

11. Shriberg LD, Kwiatkowski J. Phonological disorders III: a procedure for assessing severity of involvement. Journal of speech and Hearing Disorders. 1982;47:256-270.

12. Duanmu S. The phonology of standard Chinese. OUP Oxford; 2007.

13. An Y. A study on Korean pronunciation teaching on the final consonant for Chinese learners. Unpublished master's thesis. Chungnam National University. Daejeon; 2007.

14. Jeong MS. Strategic pronunciation instruction for learners of Korean: A case with Chinese learners of Korean. Korean Linguistics. 2008;38:345-369. 